\title{
HBV infection suppresses the expression of inflammatory macrophage miR-210
}

\author{
FEIFEI LI ${ }^{1}$, HONGJUN BIAN ${ }^{2}$, WENWEN WANG ${ }^{3}$, LIPING NING $^{4}$, MIAO XU ${ }^{5}$, \\ SHUOHUAN SUN ${ }^{1,3}$, WANHUA REN ${ }^{1,6}$, CHENGYONG QIN $^{3,6}$ and JIANNI QI ${ }^{6,7}$
}

\author{
Departments of ${ }^{1}$ Infectious Disease, ${ }^{2}$ Emergency Medicine, ${ }^{3}$ Gastroenterology and ${ }^{4}$ Rehabilitation Medicine, \\ Shandong Provincial Hospital Affiliated to Shandong University, Jinan, Shandong 250021; ${ }^{5}$ Department of Gastroenterology, \\ Jinan Hospital, Jinan, Shandong 250013; ${ }^{6}$ Shandong Provincial Engineering and Technological Research Center for \\ Liver Diseases Prevention and Control; ${ }^{7}$ Central Laboratory, Shandong Provincial Hospital \\ Affiliated to Shandong University, Jinan, Shandong 250021, P.R. China
}

Received April 23,2018; Accepted November 26, 2018

DOI: $10.3892 / \mathrm{mmr} .2018 .9795$

\begin{abstract}
It has been previously reported that hepatitis B e-antigen ( $\mathrm{HBeAg}$ ) induces microRNA (miR)-155 expression and promotes liver injury by increasing inflammatory cytokine production in macrophages. Moreover, it was previously demonstrated that miR-210 alleviates lipopolysaccharide-stimulated proinflammatory cytokine production in macrophages. In addition, accumulating evidence suggests that miR-210 is able to suppress hepatitis B virus (HBV) replication in HepG2.2.15 cells. However, it remains unclear whether miR-210, similar to miR-155, affects the progress of hepatitis B by regulating macrophage function. Reverse transcription-quantitative polymerase chain reaction analysis was used to detect miR-210 levels in serum and cells. HBV-associated antigens stimulated different types of macrophages and facilitated the observation of the effects of these antigens on miR-210 expression in macrophages. Co-culture of peripheral blood monocytes from healthy controls and the serum of patients with chronic hepatitis $\mathrm{B}(\mathrm{CHB})$ was conducted to evaluate the effect of $\mathrm{HBV}$-associated elements in the serum on the expression of the macrophage miR-210 in vivo. It was observed that miR-210 expression levels were decreased in the peripheral blood monocytes (PBMs) and serum of patients with CHB and negatively associated with serum alanine aminotransferase
\end{abstract}

Correspondence to: Dr Jianni Qi, Central Laboratory, Shandong Provincial Hospital Affiliated to Shandong University, 324 Jingwu Road, Jinan, Shandong 250021, P.R. China

E-mail: slqijn@126.com

Abbreviations: $\mathrm{HBV}$, hepatitis $\mathrm{B}$ virus; $\mathrm{HCC}$, hepatocellular carcinoma; miR-210, microRNA-210; qPCR, quantitative polymerase chain reaction; $\mathrm{CHB}$, chronic hepatitis B; PMs, peritoneal macrophages; PBMs, peripheral blood monocytes

Key words: HBV, miR-210, macrophage, inflammatory and aspartate aminotransferase, but not other clinical parameters including hepatitis B surface antigen ( $\mathrm{HBsAg}$ ), $\mathrm{HBeAg}$, anti-HBe antibody ( $\mathrm{HBeAb}$ ) and hepatitis B core antibody (HBcAb) and HBV-DNA. Notably, it was demonstrated that miR-210 expression was not affected by treatment with HBV-associated antigens in different types of macrophages. Notably, the serum of patients with $\mathrm{CHB}$ was able to markedly downregulate the miR-210 expression of PBMs in healthy controls. These findings suggested that, unlike the induction of miR-155 by HBeAg, there may be certain other elements, apart from HBV-associated antigens, regulating miR-210 levels in the serum and PBMs of patients with $\mathrm{CHB}$ that affect macrophage activation.

\section{Introduction}

MicroRNAs (miRNAs) are endogenous, evolutionarily highly conserved, small noncoding RNAs, which are derived from the genomes of eukaryotic organisms and various viruses and have multiple functions in the regulation of gene expression in animals and plants $(1,2)$. miRNA (miR)-210, a prototypical hypoxamir, is one of the most widely studied miRNAs $(3,4)$. Mounting evidence has demonstrated that miR-210 is involved in the sophisticated regulation of various biological processes, and is associated with the development and progression of different diseases, including cardiovascular, cerebrovascular and immunological diseases, in addition to numerous types of cancer. For example, Mutharasan et al (5) reported that miR-210 was markedly upregulated through Akt serine/threonine kinase 1- and tumor protein p53-dependent pathways to protect cardiomyocytes from hypoxia, leading to apoptosis in vitro. Zeng et al (6) reported that $\mathrm{miR}-210$ was significantly reduced in blood samples from stroke patients at different times compared with healthy controls. miR-210 promotes cell cycle progression by targeting MAX network transcriptional repressor and E2F transcription factor 3, disrupts normal DNA repair and increases genetic instability through a homology-dependent repair DNA repair pathway (7). miR-210 expression is decreased in patients 
with systemic lupus erythematosus and rheumatoid arthritis compared with healthy controls (8). These above data suggest that miR-210 serves an indispensable role in the pathogenesis of numerous diseases.

Inflammation is a well-known cause of cancer in humans. Being one of the most common inflammatory diseases in the world, hepatitis B virus (HBV) infection is the leading cause of hepatocellular carcinoma (HCC), particularly in Asian countries (9-11). The etiological association between HBV and HCC represents an opportunity for clinicians to prevent HCC development and alleviate the outcomes of HCC by treating HBV infection. However, current immunoprophylaxis strategies against HBV do not completely abolish HBV transmission. The molecular mechanisms by which HBV infection leads to HCC are comparatively complex. Therefore, elucidating the mechanism of HBV infection is of particular importance.

A previous study demonstrated that macrophages serve a pivotal role in immune hepatitis (12). In addition, it was reported that miR-210 downregulates lipopolysaccharide (LPS)-stimulated proinflammatory cytokine production by targeting nuclear factor- $\kappa \mathrm{B} 1$ in macrophages (13). Moreover, hepatitis B e-antigen HBeAg induces miR-155 expression to increase liver injury by increasing inflammatory cytokine production in macrophages (10). However, whether miR-210, which is similar to miR-155, may also affect HBV-induced hepatitis by altering macrophage function has not been completely elucidated.

In the present study, it was identified that miR-210 expression levels were significantly reduced in peripheral blood monocytes (PBMs) and the serum of patients with $\mathrm{CHB}$, although there was no marked correlation between miR-210 expression and HBV-associated antigens and DNA in the serum. Moreover, it was demonstrated that miR-210 expression was not affected by $\mathrm{HBV}$-associated antigens in different types of macrophages in vitro. However, it is notable that the serum of patients with CHB markedly downregulated miR-210 expression in PBMs from healthy controls.

\section{Patients and methods}

Subjects and serological tests. The present study recruited 25 subjects between April 2016 and March 2017 from Shandong Provincial Hospital Affiliated to Shandong University (Jinan, China), including 11 healthy controls and 14 patients with chronic hepatitis B (CHB). These enrolled subjects were all negative for antibodies to hepatitis A, C, D, $\mathrm{E}$ virus and human immunodeficiency virus. None of them were all autoimmune liver diseases and taking immunosuppressive drugs or anti-viral therapy more than 3 months. The standard set by the National Viral Hepatitis Conference of China in 2015 was used for the diagnosis of CHB $(14,15)$. The concentrations of alanine aminotransferase (ALT) and aspartate aminotransferase (AST) in the serum were analyzed with automatic electrochemical luminescence immunoanalyzer (Roche Cobas E602; Roche Applied Science, Pleasanton, CA, USA). The hepatitis B surface antigen (HBsAg), $\mathrm{HBeAg}$, anti-HBe antibody (HBeAb) and hepatitis B core antibody ( $\mathrm{HBcAb})$ content in serum was determined with a chemiluminescence microparticle immunoassay kit (Abbott Pharmaceutical Co., Ltd., Lake Bluff, IL, USA) using the Abbott i2000 ARCHITECT system. The HBV DNA content was detected with a fluorescent label HBV DNA quantitative kit (PerkinElmer, Inc., Waltham, MA, USA) using an ABI-7500 quantitative polymerase chain reaction (qPCR) analyzer (Applied Biosystems; Thermo Fisher Scientific, Inc., Waltham, MA, USA). The clinical characteristics of these enrolled subjects are summarized in Table I. The research protocol and consent program were approved by Shandong Provincial Hospital Affiliated to Shandong University Ethics Committee. Written informed consent was acquired from each patient for this study.

Cells and reagents. Mouse primary peritoneal macrophages (PMs), the mouse macrophage cell line RAW264.7 (American Type Culture Collection, Manassas, VA, USA), and human hepatoma cell lines HepG2 and HepG2.2.15 (Chinese Academy of Sciences, Beijing, China) were acquired and cultured as previously described (16-18). HBV-associated antigens, including hepatitis B core antigen (HBcAg; cat. no. ab119441), HBeAg (cat. no. ab91273) and HBsAg (cat. no. ab167754), were purchased from Abcam (Cambridge, MA, USA) and used as was previously described (16).

Light microscope analysis. RAW264.7 cells were treated with or without $2 \mu \mathrm{g} / \mathrm{ml} \mathrm{HBcAg}, \mathrm{HBeAg}$, HBsAg or a mixture for $24 \mathrm{~h}$. The cell morphology was observed with a light microscope (Ti-S; Nikon Corporation, Tokyo, Japan), and the original magnification was x 100 .

Acquisition of mouse primary PMs. Male C57BL/6J mice $(n=6), 6-8$ weeks old, were obtained from Shandong University Experimental Animal Center (Jinan, China). All mice were housed in specific pathogen-free conditions. The animal room was kept at $20-22^{\circ} \mathrm{C}$ under a relative humidity $40-60 \%$ and $12 \mathrm{~h} \mathrm{light/dark} \mathrm{cycle.} \mathrm{These} \mathrm{mice} \mathrm{were} \mathrm{feed} \mathrm{ad}$ libitum and had access to water. All animal experiments were undertaken in accordance with the National Institutes of Health Guide for the Care and Use of Laboratory Animals, with the approval of the Scientific Investigation Board of the Shandong Provincial Hospital Affiliated to Shandong University. Mouse primary PMs were obtained as described previously (16).

miR-210 quantification in cells or serum. Total RNA in cells and serum was extracted with the miRNeasy Mini kit, miRNeasy Serum/Plasma kit and miRNeasy Serum/Plasma Spike-In Control, according to the manufacturer's protocols, as described previously (16). For the quantification of miR-210, cDNA was obtained with the miScript II reverse transcription kit. miR-210 (cat. no. MS00003801) quantification was evaluated with the miScript SYBR Green PCR kit, according to the manufacturer's protocol as previously described (17). U6 snRNA (cat. no. MS00033740) and miR-39 (cat. no. 219610) were used as an internal control. All of the above kits were purchased from Qiagen, Inc. (Valencia, CA, USA). qPCR was performed via the following steps: $95^{\circ} \mathrm{C}$ for $15 \mathrm{~min}$, followed by 45 cycles of $95^{\circ} \mathrm{C}$ for $15 \mathrm{sec}, 55^{\circ} \mathrm{C}$ for $30 \mathrm{sec}, 70^{\circ} \mathrm{C}$ for 
Table I. Clinical characteristics of subjects.

\begin{tabular}{lcc}
\hline Category & Healthy controls & CHB \\
\hline No. cases & 11 & 14 \\
Sex, male & $8(72.73 \%)$ & $12(85.71 \%)$ \\
BMI $^{\mathrm{a}}$ & $23.72 \pm 1.84$ & $24.70 \pm 1.89$ \\
Age, years $^{\mathrm{a}}$ & $42 \pm 12.87$ & $50.5 \pm 13.94$ \\
ALT, U/1 $^{\mathrm{a}}$ & $23 \pm 9.54$ & $308.5 \pm 341.16$ \\
AST, U/1 & $21 \pm 7.14$ & $222 \pm 254.71$ \\
HBV DNA positive, & 0 & $7(50 \%)$ \\
$>10^{3}$ copies/ml & & $14(100 \%)$ \\
HBsAg positive & 0 & 8 \\
HBeAg positive & 0 & 7 \\
HBeAb positive & 0 & 4 \\
HBcAb positive & 0 & \\
\hline
\end{tabular}

${ }^{a}$ Median \pm standard deviation. CHB, chronic hepatitis B; BMI, body mass index; ALT, alanine aminotransferase; AST, aspartate aminotransferase; $\mathrm{HBV}$, hepatitis $\mathrm{B}$ virus; $\mathrm{HBcAb}$, hepatitis $\mathrm{B}$ core antibody; $\mathrm{HBeAg}$, hepatitis $\mathrm{B}$ e-antigen; $\mathrm{HBeAb}$, anti-HBe antibody.

$30 \mathrm{sec}$ and $65^{\circ} \mathrm{C}$ for $30 \mathrm{sec}$, using the LightCycler Real-time PCR System (Roche Diagnostics, Indianapolis, IN, USA), as described previously (18).

Co-culture and HBV-associated antigen treatment experiments in vitro. A total of $\sim 4 \times 10^{5} / \mathrm{ml}$ macrophages were seeded and adhered to the lower chamber of a Transwell plate using Dulbecco's modified Eagle's medium (Gibco; Thermo Fisher Scientific, Inc.) with $10 \%$ fetal bovine serum (Gibco ${ }^{\circledR}$ Sera; Thermo Fisher Scientific, Inc.). Subsequently, 3x10 $/ \mathrm{ml}$ HepG2/HepG2.2.15 cells were added into the upper chambers in the same medium. Co-incubation was performed for 12, 24, 36 and $48 \mathrm{~h}$ at $37^{\circ} \mathrm{C}$ in a humidified incubator with $5 \% \mathrm{CO}_{2}$. Mouse primary PMs, mouse macrophage RAW264.7 cells, and human PBMs were stimulated with individual HBV-associated antigens $(2 \mu \mathrm{g} / \mathrm{ml})$ or a mixture for 24,36 or $48 \mathrm{~h}$. These cells were harvested using TRIzol ${ }^{\circledR}$ (Thermo Fisher Scientific, Inc.) for the evaluation of miR-210 expression levels by qPCR.

Cross culture of cell and serum. The serum was collected from $15 \mathrm{ml}$ whole blood of healthy controls and patients with $\mathrm{CHB}$ by centrifuging at $1,000 \times \mathrm{g}$ for $5-10 \mathrm{~min}$ at $20-25^{\circ} \mathrm{C}$. PBMs from healthy controls were obtained by density gradient centrifugation $\left(780 \mathrm{x} \mathrm{g}\right.$ for $20-30 \mathrm{~min}$ at $20-25^{\circ} \mathrm{C}$ ) and seeded in a 12-well plate with complete medium of RPMI-1640 (Gibco ${ }^{\circledR}$; Thermo Fisher Scientific, Inc.) with $10 \%$ FBS overnight for attachment. The following day, the suspended cells were removed and the adherent cells were incubated with their own serum or serum from patients with $\mathrm{CHB}$ for $36 \mathrm{~h}$. These PBMs were harvested with TRIzol to extract the total RNA. A reverse transcription experiment was performed, and the expression of miR-210 was detected with the corresponding kits, as described above.

Statistical analysis. Data are presented as the mean \pm standard deviation. All statistical analyses were performed using
GraphPad Prism 5 software (GraphPad Software, Inc., La Jolla, CA, USA). Student's t-tests were used to verify significant differences between two groups. One-way analysis of variance followed by the least significant difference post hoc test was used to assess significant differences between the different treatments. Spearman correlation analysis was performed between miR-210 expression and serum ALT, AST, HBsAg, HBeAg, HBeAb, HBcAb or HBV DNA levels. $\mathrm{P}<0.05$ was considered to indicate a statistically significant difference.

\section{Results}

miR-210 expression is decreased, and is negatively correlated with serum ALT and AST. To evaluate the effect of miR-210 on HBV infection, PBMs and serum were collected from patients with $\mathrm{CHB}$ or healthy controls and miR-210 expression was assessed. As presented in Figs. 1 and 2, the expression of miR-210 was significantly decreased in PBMs (Fig. 1A) and serum (Fig. 2A). The associations between the expression of miR-210 and multiple clinical parameters were also assessed. miR-210 expression was negatively correlated with serum ALT and AST; the correlation coefficients were -0.5868 and -0.7231 , and -0.7319 and -0.5692 , respectively (Figs. 1B, C; 2B and C). There was no marked correlation between miR-210 expression and $\mathrm{HBsAg}, \mathrm{HBeAg}, \mathrm{HBeAb}, \mathrm{HBcAb}$ and HBV-DNA in the serum (Figs. 1D-H; 2D-H). Taken together, miR-210 expression was reduced in the PBMs and serum of patients with $\mathrm{CHB}$ and was inversely correlated with serum ALT and AST, but there was no correlation with other HBV infection-associated clinical indexes.

miR-210 expression is not affected by $H B V$-associated antigens in different types of macrophages. A previous study demonstrated that $\mathrm{HBeAg}$ is able to promote the production of macrophage inflammatory factors and the expression of miR-155, by miRNA sequencing and a qPCR approach (16). miR-210 expression was also decreased in this miRNA sequencing analysis. However, the effect and mechanism of miR-210 on macrophage activation has not been completely elucidated. Therefore, in the present study, RAW264.7 macrophages were stimulated with HBV-associated antigens for $24 \mathrm{~h}$. As presented in Fig. 3A, as previously reported, RAW264.7 cells were elongated with multiple pseudopodia in the $\mathrm{HBeAg}$ and mix groups. Subsequently, miR-210 expression was detected in RAW264.7 macrophages with different $\mathrm{HBV}$-associated antigens at different times. As presented in Fig. 3B, the expression of miR-210 was not altered by the different antigens or at different time points in RAW264.7 cells. To eliminate the possibility that the cell type led to this lack of change, mouse primary PMs and human PBMs were acquired and stimulated with $\mathrm{HBV}$-associated antigens. It was observed that $\mathrm{HBeAg}$ was able to induce miR-210 expression, but the increase was not significant in these different types of macrophages (Fig. 3C and D). Taken together, although miRNA sequencing (16) indicated that miR-210 expression was decreased, there was no notable difference between the different types of macrophages under treatment with $\mathrm{HBV}$-associated antigens, according to the qPCR analysis.

Serum from patients with $C H B$ markedly downregulated the miR-210 expression of PBMs from healthy controls. To observe 
A

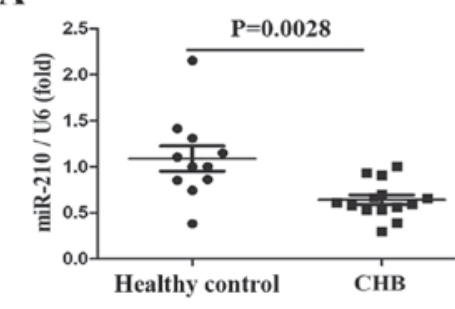

D

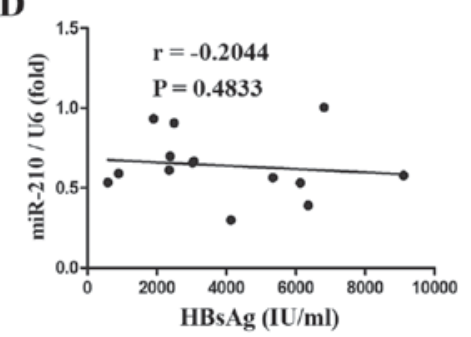

G

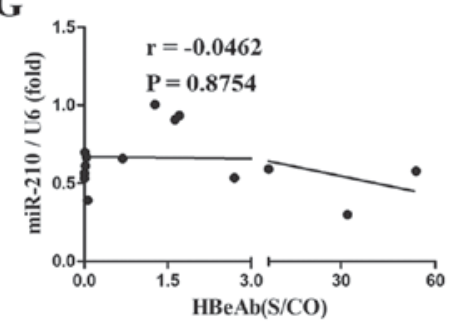

B

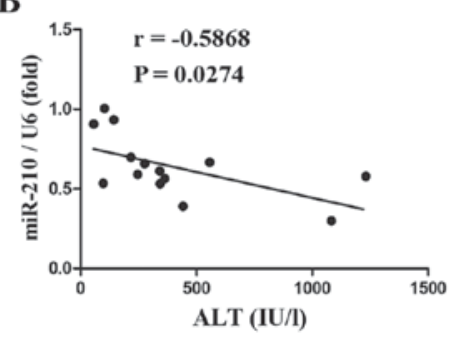

$\mathbf{E}$

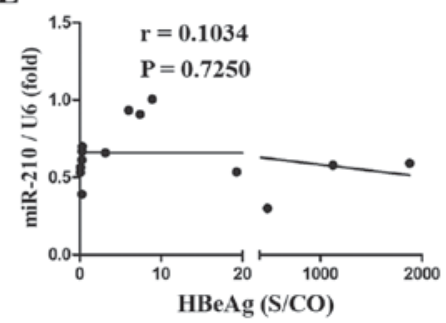

H

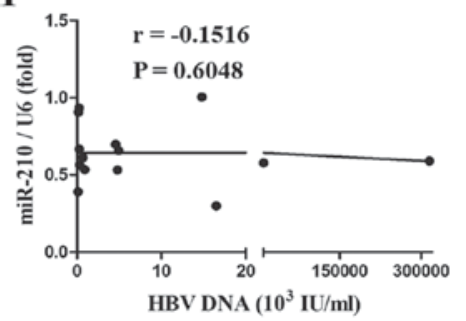

C

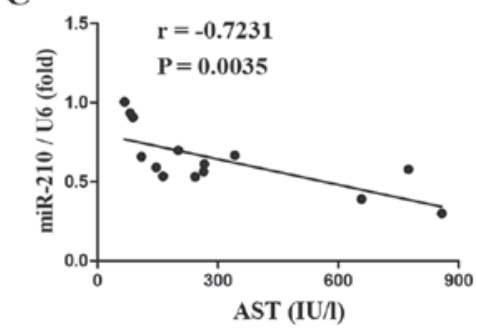

$\mathbf{F}$

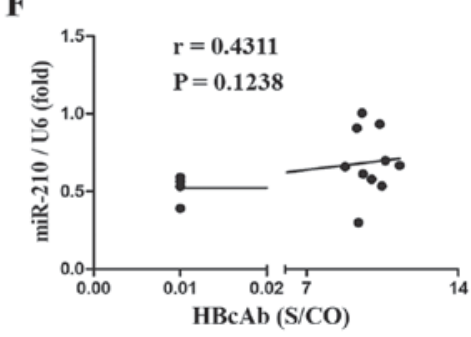

Figure 1. miR-210 expression is decreased in the PBMs of patients with CHB, and is negatively correlated with serum ALT and AST. (A) miR-210 expression was detected by quantitative polymerase chain reaction in the PBMs of healthy controls and patients with CHB. Data are presented as the mean \pm standard deviation of triplicate experiments. The correlation between the expression of miR-210 and the (B) ALT, (C) AST, (D) HBsAg, (E) HBeAg, (F) HBcAb, (G) HBeAb or (H) HBV-DNA content was analyzed. $r$ represents the Spearman correlation coefficient. Data are representative of three independent experiments. PBMs, peripheral blood monocytes; ALT, alanine aminotransferase; AST, aspartate aminotransferase; HBsAG, hepatitis B surface antigen; HBeAg, hepatitis B e-antigen; $\mathrm{HBeAb}$, anti-HBe antibody; HBcAb, hepatitis B core antibody; CHB, chronic hepatitis B; S/CO, Sample/Cut Off; miR, microRNA; HBV, hepatitis B virus.

the effect of HBV infection on miR-210 expression in vivo, PBMs were obtained from healthy controls and treated with the serum of patients with CHB. As illustrated in Fig. 4, it was identified that the serum of patients with $\mathrm{CHB}$ was able to significantly reduce the miR-210 expression of PBMs from healthy controls.

\section{Discussion}

The precursor of miR-210 forms a stem-loop structure and is located within the intron region of AK123483 gene, which is located on chromosome 11p15.5 (19). The gene sequence of miR-210 is evolutionarily conserved between different species, indicating its functional importance $(20,21)$. Convincing evidence suggests that miR-210 is widely expressed in multiple tissues and cells, including hematopoietic stem cells, numerous cancer cells, myeloid cells and lymphocytes (22-25). miR-210 is a pivotal hypoxia-response factor in numerous diseases (26). Faraonio et al (27) reported that miR-210 was aberrantly overexpressed in senescent human diploid fibroblasts, leading to an increase in DNA damage and the repression of cell proliferation. Bar et al (28) reported that miR-210 is highly expressed in cells of the triple-negative breast cancer subtype, and in the tumor microenvironment, and its overexpression has been linked to poor prognosis. In addition, miR-210 was induced after photodynamic therapy in HeLa cells (29). Surprisingly, the increased expression of miR-210 has an exceptionally long half-life and does not rapidly return to normal levels after hypoxic exposure for $24 \mathrm{~h}$ (30). In addition, although there were also reports that miR-210 levels in serum may predict HBV replication and translation (31) and the virological response to treatment with interferon- $\alpha$ in patients with CHB (32), the role and mechanism of miR-210 in HBV infection was not elucidated. Notably, it was previously reported that miR-210 in murine macrophages negatively regulates the LPS-induced production of proinflammatory cytokines (13). Therefore, it was hypothesized that HBV-associated antigens may activate macrophages in a similar manner to LPS and induce the expression of miR-210, to ultimately regulate their function in HBV infection.

In the present study, the results demonstrated that miR-210 expression was significantly diminished in the PBMs and serum of patients with $\mathrm{CHB}$, but there was not a marked correlation between miR-210 expression and $\mathrm{HBsAg}, \mathrm{HBeAg}, \mathrm{HBeAb}$, $\mathrm{HBcAb}$ and $\mathrm{HBV}$-DNA in the serum. A number of studies have shown that the expression of certain stress proteins (including heat shock proteins and $\mathrm{C}$-reactive proteins) are increased during HBV infection $(33,34)$. Moreover, these proteins may affect macrophage activation $(35,36)$. Therefore, it was speculated that the expression of macrophage miR-210 may be affected by these stress proteins or other unknown factors during HBV infection. The present study used the traditional adherent separation 
A

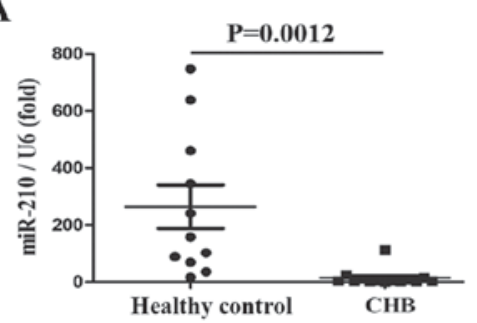

D

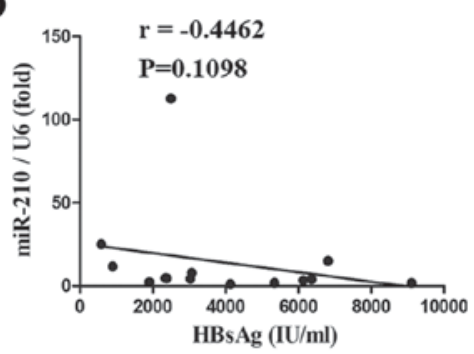

G

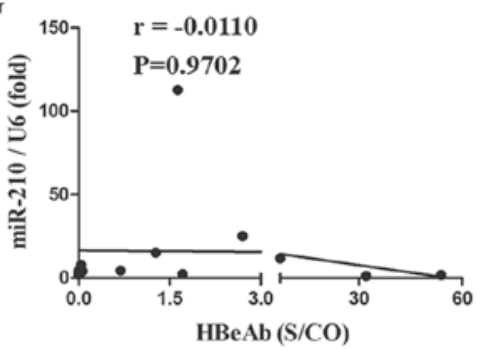

B

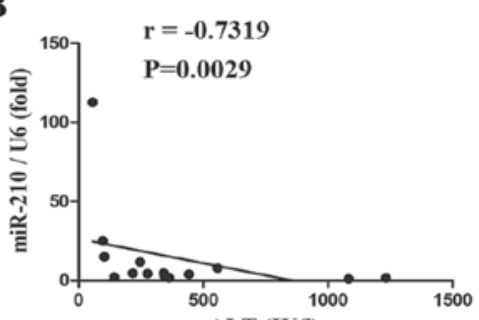

E

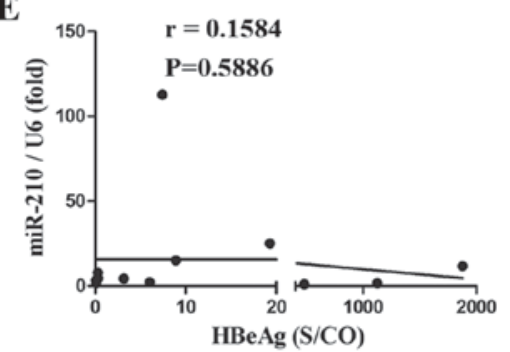

H

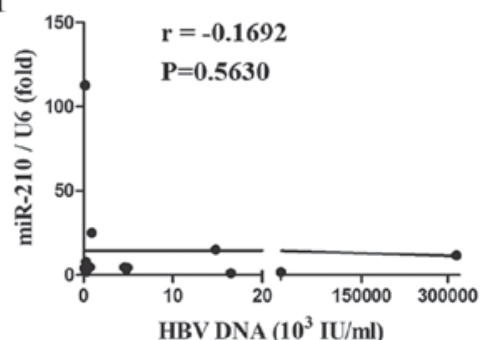

C

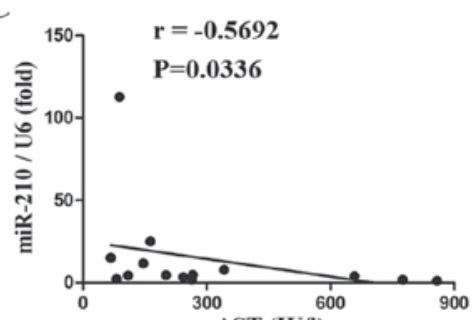

F

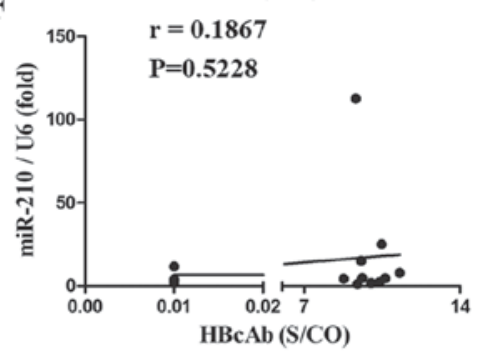

Figure 2. miR-210 expression is decreased in the serum of patients with CHB, and is negatively correlated with serum ALT and AST. (A) miR-210 expression was measured by quantitative polymerase chain reaction in the serum of healthy controls and patients with CHB. Data are presented as the mean \pm standard deviation of triplicate experiments. The correlation between the expression of miR-210 and (B) ALT, (C) AST, (D) HBsAg, (E) HBeAg, (F) HBcAb, (G) HBeAb or (H) HBV-DNA content was analyzed. $r$ represents the Spearman correlation coefficient. Data are representative of three independent experiments. ALT, alanine aminotransferase; AST, aspartate aminotransferase; HBsAG, hepatitis B surface antigen; HBeAg, hepatitis B e-antigen; HBeAb, anti-HBe antibody; HBcAb, hepatitis B core antibody; CHB, chronic hepatitis B; S/CO, Sample/Cut Off; miR, microRNA; HBV, hepatitis B virus.

$\mathbf{A}$

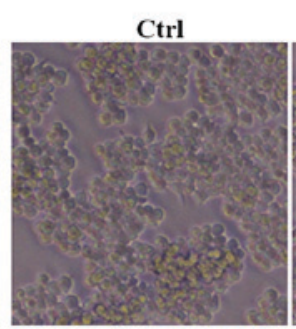

B

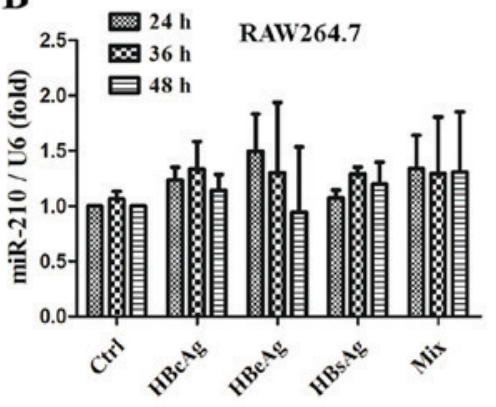

HBcAg

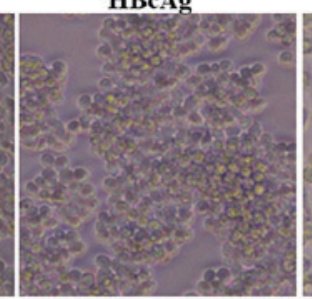

C
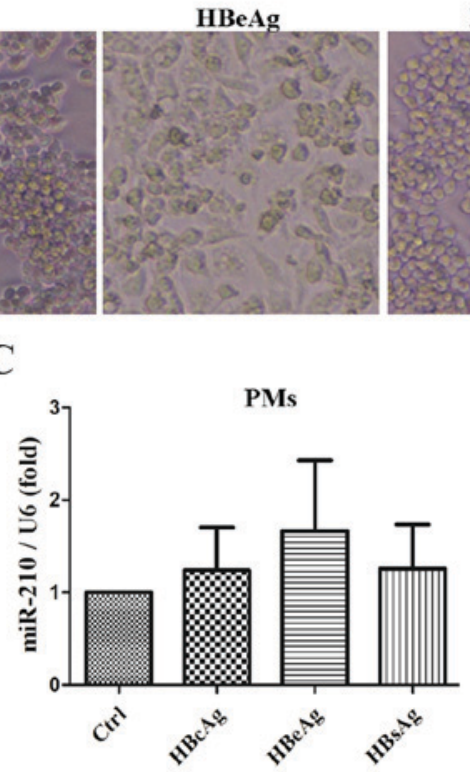

HBsAg

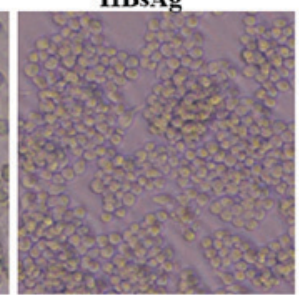

D

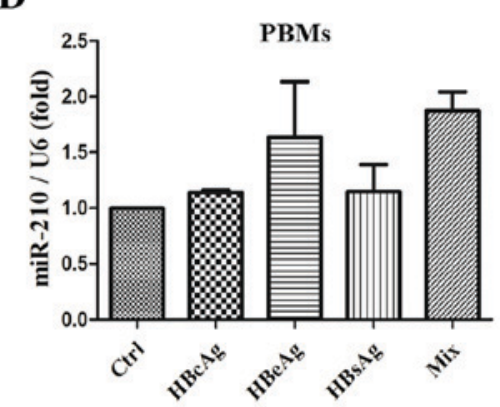

Figure 3. miR-210 expression is not affected by HBV-associated antigens in different types of macrophages. RAW264.7 cells were treated with $\mathrm{HBcAg}, \mathrm{HBeAg}$, HBsAg or a mixture $(2 \mu \mathrm{g} / \mathrm{ml})$ for 24,36 or $48 \mathrm{~h}$. (A) The cell morphology was observed with a light microscope (original magnification, $\mathrm{x} 100)$. (B) The expression of miR-210 was tested by qPCR. (C) Mouse primary PMs and (D) PBMs of healthy controls were stimulated with $\mathrm{HBcAg}, \mathrm{HBeAg}, \mathrm{HBsAg}$ or a mixture $(2 \mu \mathrm{g} / \mathrm{ml})$ for $36 \mathrm{~h}$. The expression of miR-210 was detected by qPCR. Data are representative of three independent experiments (mean \pm standard deviation). PMs, peritoneal macrophages; PBMs, peripheral blood monocytes; miR, microRNA; HBcAg, hepatitis B core antigen; HBeAg, hepatitis B e-antigen; HBsAG, hepatitis B surface antigen; qPCR, quantitative polymerase chain reaction. 
method, as described previously (16). This assay is relatively weak compared with fluorescence-activated cell sorting (FACS), but it is more readily available. In addition, since the small sample size was a limitation of the current study, the differences between male and female subjects were not compared. Therefore, future studies may expand the sample content and/or use a FACS assay to detect the effects and mechanisms of miR-210 or other miRs during HBV infection. The detection of these serum miRs as an important indicator may be a basis for observing the immune status of patients with $\mathrm{HBV}$ infection.

When liver cells are infected by HBV, they experience an immune attack, leading to acute and chronic inflammatory responses in the liver. In CHB, the virus is frequently maintained at a low level over a long period (37). The number of patients with $\mathrm{CHB}$, and the gradually increasing trend of liver cirrhosis and HCC, has led to large expenditure for medical treatment, representing a serious health burden in worldwide, but particularly in China (38). Therefore, early diagnosis and treatment may be a good therapeutic strategy to avoid disease progression, including the prevention of liver fibrosis and HCC. However, the factors that regulate the development of CHB have not been clearly identified. It has been indicated that once individuals are infected with HBV, the HBV DNA converts into covalently closed circular DNA to promote viral DNA replication. In addition, various viral proteins are produced, including $\mathrm{HBsAg}, \mathrm{HBcAg}$ and $\mathrm{HBeAg}$, resulting in the activation of the immune system (39). It was previously reported that $\mathrm{HBeAg}$ is able to promote miR-155 expression to enhance liver damage by elevating inflammatory cytokine production in macrophages (16). However, less is known about the effect of HBV-associated antigens on hypoxic miR-210. It has been reported that PBMs may be directly stimulated in vitro $(16,40-42)$. There have also been reports that $\mathrm{PBMs}$ may be induced to become M1 or M2 macrophages by exposure to granulocyte-macrophage colony-stimulating factor or macrophage colony-stimulating factor (43). Therefore, the PBMs in the present study were not treated with GM-CSF to avoid the induction of monocyte activation not by HBV-associated antigens. In the present study, the results demonstrated that HBV-associated antigens have no effect on the expression of miR-210 in different types of macrophages from mice and humans, including cell lines and primary macrophages. However, it was demonstrated that the serum of patients with CHB was able to significantly diminish the miR-210 expression of PBMs from healthy controls.

In conclusion, it was observed that miR-210 expression was markedly decreased in the PBMs and serum of patients with CHB. Subsequently, the association between miR-210 expression and multiple clinical indexes in HBV infection was assessed, and it was observed that there was not a marked correlation between them. In vitro, it was demonstrated that $\mathrm{HBV}$-associated antigens had no effect on miR-210 expression in macrophages. Notably, the serum of patients with CHB was able to impair miR-210 expression in PBMs from healthy controls. Therefore, these findings suggest that there may be another regulatory mechanism of miR-210 expression in HBV infection.

\section{Acknowledgements}

The authors would like to thank Professor Qiang Zhu for helping with language editing.

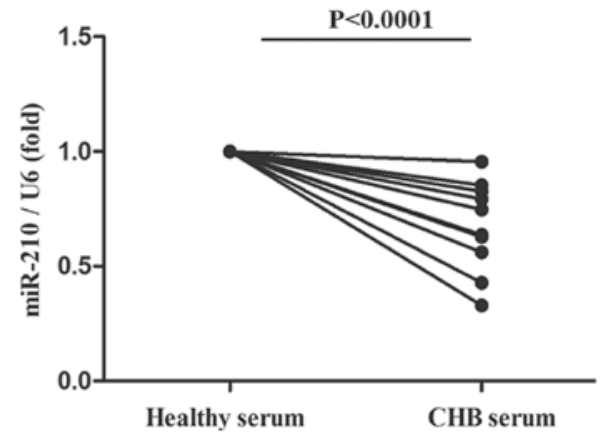

Figure 4. Serum from patients with CHB markedly downregulates miR-210 expression in PBMs from healthy controls. PBMs of healthy controls were collected and cultured with the serum of healthy controls or patients with CHB. Data are representative of three independent experiments (mean \pm standard deviation of triplicate samples). PBMs, peripheral blood monocytes; CHB, chronic hepatitis B.

\section{Funding}

The present study was supported by the National Natural Science Foundation of China (grant nos. 81600469, 81772626, 81871700 and 81401868), the Science and Technology Development Projects of Shandong Province (grant no. 2017GSF218053), the Clinical Medical Science and Technology Innovation Program of Jinan City (grant no. 201704114), the Natural Science Foundation of Shandong Province (grant no. ZR2018PH003), and the Shandong Province Medical and Health Science and Technology Development Project (grant nos. 2017WS194 and 2017WS465).

\section{Availability of data and materials}

The authors confirm that all data and materials are fully available without any restriction. All relevant data are within the paper.

\section{Authors' contributions}

JQ, HB and CQ conceived and designed the experiments. FL and WW performed the experiments. WR and SS analyzed the data. LN and MX collected clinical samples, fed the mice and assisted with the experiments. HB and JQ wrote the manuscript.

\section{Ethics approval and consent to participate}

The research protocol and consent program were approved by Shandong Provincial Hospital Affiliated to Shandong University Ethics Committee. Written informed consent was acquired from each patient for this study. All animal experiments were undertaken in accordance with the National Institutes of Health Guide for the Care and Use of Laboratory Animals, with the approval of the Scientific Investigation Board of the Shandong Provincial Hospital Affiliated to Shandong University.

\section{Patient consent for publication}

Not applicable.

\section{Competing interests}

The authors declare that they have no competing interests. 


\section{References}

1. Nguyen TH, Liu X, Su ZZ, Hsu AC, Foster PS and Yang M: Potential role of MicroRNAs in the regulation of antiviral responses to influenza infection. Front Immunol 9: 1541, 2018.

2. Wei Y, Zhu M and Schober A: Macrophage MicroRNAs as therapeutic targets for atherosclerosis, metabolic syndrome, and cancer. Int J Mol Sci 19: E1756, 2018.

3. Chan YC, Banerjee J, Choi SY and Sen CK: miR-210: The master hypoxamir. Microcirculation 19: 215-223, 2012.

4. Chan SY and Loscalzo J: MicroRNA-210: A unique and pleiotropic hypoxamir. Cell Cycle 9: 1072-1083, 2010.

5. Mutharasan RK, Nagpal V, Ichikawa Y and Ardehali H: microRNA-210 is upregulated in hypoxic cardiomyocytes through Akt- and p53-dependent pathways and exerts cytoprotective effects. Am J Physiol Heart Circ Phyiol 301: H1519-H1530, 2011.

6. Zeng L, Liu J, Wang Y, Wang L, Weng S, Tang Y, Zheng C, Cheng Q, Chen S and Yang GY: MicroRNA-210 as a novel blood biomarker in acute cerebral ischemia. Front Biosci (Elite Ed) 3: $1265-1272,2011$.

7. Dang K and Myers KAL: The role of hypoxia-induced miR-210 in cancer progression. Int J Mol Sci 16: 6353-6372, 2015.

8. Huang Q, Chen SS, Li J, Tao SS, Wang M, Leng RX, Pan HF and Ye DQ: miR-210 expression in PBMCs from patients with systemic lupus erythematosus and rheumatoid arthritis. Ir J Med Sci 187: 243-249, 2018.

9. Chan SL, Wong VW, Qin S and Chan HL: Infection and cancer: The case of hepatitis B. J Clin Oncol 34: 83-90, 2016.

10. Wen WH, Huang CW, Chie WC, Yeung CY, Zhao LL, Lin WT, Wu JF, Ni YH, Hsu HY, Chang MH, et al: Quantitative maternal hepatitis B surface antigen predicts maternally transmitted hepatitis B virus infection. Hepatology 64: 1451-1461, 2016.

11. Niller HH, Ay E, Banati F, Demcsák A, Takacs $M$ and Minarovits J: Wild type HBx and truncated HBx: Pleiotropic regulators driving sequential genetic and epigenetic steps of hepatocarcinogenesis and progression of $\mathrm{HBV}$-associated neoplasms. Rev Med Virol 26: 57-73, 2016.

12. Xu L, Qi J,Zhao P,Liang X, Ju Y, Liu P, Liu B, Guo C, Zhang L, Ma C and Gao L: T cell immunoglobulin- and mucin-domain-containing molecule- 4 attenuates concanavalin A-induced hepatitis by regulating macrophage. J Leukoc Biol 88: 329-336, 2010.

13. Qi J, Qiao Y, Wang P, Li S, Zhao W and Gao C: MicroRNA-210 negatively regulates LPS-induced production of proinflammatory cytokines by targeting NF- $\kappa \mathrm{B} 1$ in murine macrophages. FEBS Lett 586: 1201-1207, 2012.

14. Chinese Society of Infectious Diseases, Chinese Medical Association, Chinese Society of Infectious Diseases, Chinese Medical Association, Hou JL and Lai W: The guideline of prevention and treatment for chronic hepatitis B: A 2015 update. Zhonghua Gan Zang Bing Za Zhi (In Chinese) 23: 888-905, 2015

15. Hou J, Wang G, Wang F, Cheng J, Ren H, Zhuang H, Sun J, Li L, Li J, Meng Q, et al: Guideline of prevention and treatment for chronic hepatitis B (2015 Update). J Clin Transl Hepatol 5: 297-318, 2017.

16. Wang W, Bian H, Li F, Li X, Zhang D, Sun S, Song S, Zhu Q, Ren W, Qin C and Qi J: HBeAg induces the expression of macrophage miR-155 to accelerate liver injury via promoting production of inflammatory cytokines. Cell Mol Life Sci 75: 2627-2641, 2018.

17. Bian H, Li F, Wang W, Zhao Q, Gao S, Ma J, Li X, Ren W, Qin C and Qi J: MAPK/p38 regulation of cytoskeleton rearrangement accelerates induction of macrophage activation by TLR4, but not TLR3. Int J Mol Med 40: 1495-1503, 2017.

18. Qi J, Li T, Bian H, Li F, Ju Y, Gao S, Su J, Ren W and Qin C: SNAI1 promotes the development of HCC through the enhancement of proliferation and inhibition of apoptosis. FEBS Open Bio 6: 326-337, 2016.

19. Camps C, Buffa FM, Colella S, Moore J, Sotiriou C, Sheldon H, Harris AL, Gleadle JM and Ragoussis J: hsa-miR-210 is induced by hypoxia and is an independent prognostic factor in breast cancer. Clin Cancer Res 14: 1340-1348, 2008.

20. Huang X, Ding L, Bennewith KL, Tong RT, Welford SM, Ang KK, Story M, Le QT and Giaccia AJ: Hypoxia-inducible mir-210 regulates normoxic gene expression involved in tumor initiation. Mol Cell 35: 856-867, 2009.

21. Ren CX, Leng RX, Fan YG, Pan HF, Wu CH and Ye DQ: MicroRNA-210 and its theranostic potential. Expert Opin Ther Targets 20: 1325-1338, 2016.

22. Huang X, Le QT and Giaccia AJ: MiR-210-micromanager of the hypoxia pathway. Trends Mol Med 16: 230-237, 2010.
23. Jiang Y, Li L, Tan X, Liu B, Zhang Y and Li C: miR-210 mediates vagus nerve stimulation-induced antioxidant stress and anti-apoptosis reactions following cerebral ischemia/reperfusion injury in rats. J Neurochem 134: 173-181, 2015.

24. Noman MZ, Buart S, Romero P, Ketari S, Janji B, Mari B, Mami-Chouaib F and Chouaib S: Hypoxia-inducible miR-210 regulates the susceptibility of tumor cells to lysis by cytotoxic T cells. Cancer Res 72: 4629-4641, 2012.

25. Chen Z, Li Y,Zhang H, Huang P and Luthra R: Hypoxia-regulated microRNA-210 modulates mitochondrial function and decreases ISCU and COX10 expression. Oncogene 29: 4362-4368, 2010.

26. Li C, Zhao M, Zhang C, Zhang W, Zhao X, Duan X and Xu W: miR210 modulates respiratory burst in apostichopus japonicas coelomocytes via targeting toll-like receptor. Dev Comp Immunol 65: 377-381, 2016.

27. Faraonio R, Salerno P, Passaro F, Sedia C, Iaccio A, Bellelli R, Nappi TC, Comegna M, Romano S, Salvatore G, et al: A set of miRNAs participates in the cellular senescence program in human diploid fibroblasts. Cell Death Differ 19: 713-721, 2012.

28. Bar I, Merhi A, Abdel-Sater F, Ben Addi A, Sollennita S, Canon JL and Delrée P: The microRNA miR-210 is expressed by cancer cells but also by the tumor microenvironment in triple-negative breast cancer. J Histochem Cytochem 65: 335-346, 2017.

29. Kushibiki T: Photodynamic therapy induces microRNA-210 and -296 expression in HeLa cells. J Biophotonics 3: 368-372, 2010.

30. Fasanaro P, D'Alessandra Y, Di Stefano V, Melchionna R, Romani S, Pompilio G, Capogrossi MC and Martelli F: MicroRNA-210 modulates endothelial cell response to hypoxia and inhibits the receptor tyrosine kinase ligand Ephrin-A3. J Biol Chem 283: 15878-15883, 2008.

31. Yu F, Yang J, Ouyang J, Zheng Y, Chen B, Li G, Lu Z, Dong P and Zheng J: Serum microRNA-210 levels in different groups of chronic hepatitis B patients. Clin Chim Acta 450: 203-209, 2015.

32. Li J, Zhang X, Chen L, Zhang Z, Zhang J, Wang W, Wu M, Shi B, Zhang X, Kozlowski M, et al: Circulating miR-210 and miR-22 combined with ALT predict the virological response to interferon-alpha therapy of CHB patients. Sci Rep 7: 15658, 2017.

33. Wyżewski Z, Gregorczyk KP, Szczepanowska J and Szulc-Dąbrowska L: Functional role of Hsp60 as a positive regulator of human viral infection progression. Acta Virol 62: 33-40, 2018.

34. Hao S, Wang Y, Gao G and Li Z: Hepatitis B virus upregulates the expression of $\mathrm{C}$-reactive protein both in vivo and in vitro. Ann Clin Lab Sci 47: 432-435, 2017.

35. Vega VL, Rodríguez-Silva M, Frey T, Gehrmann M, Diaz JC, Steinem C, Multhoff G, Arispe N and De Maio A: Hsp70 translocates into the plasma membrane after stress and is released into the extracellular environment in a membrane-associated form that activates macrophages. J Immunol 180: 4299-42307, 2008.

36. Pilling D, Galvis-Carvajal E, Karhadkar TR, Cox N and Gomer RH: Monocyte differentiation and macrophage priming are regulated differentially by pentraxins and their ligands. BMC Immunol 18: 30, 2017.

37. Karayiannis P: Hepatitis B virus: Virology, molecular biology, life cycle and intrahepatic spread. Hepatol Int 11: 500-508, 2017.

38. WHO: Hepatitis B. http://www.who.int/en/news-room/factsheets/detail/hepatitis-b. Accessed July 2018.

39. Stramer SL, Wend U, Candotti D, Foster GA, Hollinger FB, Dodd RY, Allain JP and Gerlich W: Nucleic acid testing to detect HBV infection in blood donors. N Engl J Med 364: 236-247, 2011.

40. Justo-Junior AS, Villarejos LM, Lima XTV, Nadruz W Jr, Sposito AC, Mamoni RL, Abdalla R, Fernandes JL, Oliveira RTD and Blotta MHSL: Monocytes of patients with unstable angina express high levels of chemokine and pattern-recognition receptors. Cytokine, 2018.

41. Gu X, Wei C, Zhu X, Lu F, Sheng B and Zang X: Effect of interleukin-31 on septic shock through regulating inflammasomes and interleukin-1 $\beta$. Exp Ther Med 16: 171-177, 2018

42. Santoni G, Morelli MB, Amantini C, Santoni M, Nabissi M, Marinelli $\mathrm{O}$ and Santoni A: Immuno-transient receptor potential ion channels: The role in monocyte- and macrophage-mediated inflammatory responses. Front Immunol 9: 1273, 2018.

43. Schneider A, Weier M, Herderschee J, Perreau M, Calandra T, Roger T and Giannoni E: IRF5 is a key regulator of macrophage response to lipopolysaccharide in newborns. Front Immunol 9: $1597,2018$. 